\title{
Study on the Effective Operation Mechanism of School Gymnasium opening to Society
}

\author{
Youfeng Wang ${ }^{1}$ \\ ${ }^{1}$ Oxbridge College, Kunming University of Science and Technology, Kunming, Yunnan, China
}

Keywords: school gymnasium; society; open; operation mechanism.

\begin{abstract}
This article studied on the issue of school gymnasium to society through interviewing and then explore the flaw of such operation mechanism to build a sound base for its being better, which could improve the open level of school gymnasium, complete the fitness service system and offer the conference to the integration of national fitness resource.
\end{abstract}

\section{Introduction}

The insufficient of public sports equipment at present causes the group sports can't run normally. If primary and secondary schools could offer their gymnasium to the public, it will improve the asset efficiency and the harmony in community. Only to build a set of operation to match the reality with school gymnasium then we could construct well opening atmosphere and push the opening work effectively, healthy and continually.

\section{Background of research}

The steady development of social economy improve the level of people's material and spiritual life, meanwhile their life style changed gradually and concentrate on fitness. Sports also changed from educational scale into social life. As national fitness is flourish, people those take part in sports exercise become more an more. However, influenced by the number of gymnasium and open volume, people' fitness command couldn't be gratified. After statistics, we find that our sports population in proportion is nearly 65\% in 2016, but for insufficient sports resource and bills due in public sports equipments, the public sports career couldn't develop continually.[1] Therefore, to meet the fitness command of people we should take great advantages of school gymnasium and build fine sports environment and condition, it is not only the practical command of national constructing service system but also the fundamental to improve national assets level and social harmony.

\section{Related research review}

According to the related analysis result, the opening rate our university gymnasiums at present is around $64 \%$, secondary school and primary school are 59\% and $27 \%$, the whole level of them is that university id better than secondary and primary schools, because the number and kinds of university is more than others, the location of it also in the big city with high sports command as well.

Lee Chunlan thought that opening of school gymnasium should be reasonable and to strengthen its service consciousness, with the circumstance of not influence school sports teaching, choosing a right timing for opening. It is need to complete gymnasium system, improving opening level and usage rate and thus make a sound base of national fitness level.

\section{Subjects and methods in research}

Subjects in research. In order to build a well opening system of school gymnasium, this article took 11 universities from one city as subjects, and used Questionnaire survey to study on the opening system of gymnasium and its restrict factors. 


\section{Methods in research}

Mathematical statistics. The article used Soft SPSS11.5 to make a mathematic statistic on the related data of subjects in research.

Questionnaire survey. To design questionnaire and check the efficiency. Before programming the questionnaire survey, the writer look through several books on sports scientific research and social survey to prepare a well theory basis, and following the questionnaire design command of related sports scientific research to design it. [2] The concrete method is: the professions will amend the original questionnaire again and again and then let the taken school professions to check it. The concrete result of questionnaire efficiency of it could see in form 1. The feedback of it as following: the proportion of nearly reasonable, reasonable, very unreasonable are $9.08 \%, 9.08 \%$, and $81.84 \%$; the feedback of questionnaire design are $9.09 \%$ in nearly reasonable, $27.27 \%$ in reasonable and $63.65 \%$ in very unreasonable, it shows the efficiency of the questionnaire is quiet high. [3]

Form 1 the result of questionnaire efficiency

\begin{tabular}{|l|l|l|l|l|l|l|}
\hline \multicolumn{2}{|c|}{ Evaluation content } & \multicolumn{1}{|c|}{$\begin{array}{l}\text { Very } \\
\text { unreasonable }\end{array}$} & $\begin{array}{l}\text { Not very } \\
\text { reasonable }\end{array}$ & $\begin{array}{l}\text { Nearly } \\
\text { reasonable }\end{array}$ & reasonable & \multicolumn{1}{|l|}{$\begin{array}{l}\text { Very } \\
\text { reasonable }\end{array}$} \\
\hline \multirow{2}{*}{$\begin{array}{l}\text { content } \\
\text { design }\end{array}$} & $\begin{array}{l}\text { Number } \\
\text { of } \\
\text { people }\end{array}$ & 0 & 0 & 1 & 1 & 9 \\
\cline { 2 - 8 }$\%$ & 0 & 0 & 9.08 & 9.08 & 81.84 \\
\hline \multirow{2}{*}{$\begin{array}{l}\text { Constru- } \\
\text { ction } \\
\text { design }\end{array}$} & $\begin{array}{l}\text { Number } \\
\text { of } \\
\text { people }\end{array}$ & 0 & 0 & 1 & 3 & 7 \\
\cline { 2 - 8 }$\%$ & 0 & 0 & 9.08 & 27.27 & 63.65 \\
\hline \multirow{2}{*}{$\begin{array}{l}\text { Whole } \\
\text { design }\end{array}$} & $\begin{array}{l}\text { Number } \\
\text { of }\end{array}$ & 0 & 0 & 1 & 3 & 7 \\
\cline { 2 - 8 } & $\%$ & 0 & 0 & 9.08 & 27.27 & 63.65 \\
\hline
\end{tabular}

To issue and return the questionnaire. The article takes 11 schools as subjects in survey, and these school gymnasiums were already opened to society. To take these opened school as questionnaire subjects could make a more clear understand of their opening situations.[4] The questionnaire were handed out in mid-Oct and late Oct. 2016, and the subjects are sports teachers and school leaders. In order to ensure the feedback rate of questionnaire, we handed out it in the scene and book the time to collect it. The timing to hand out is in Oct.17,2016 and the return timing is Oct.24, 2016. There were 85 questionnaires handed out, 82 copies returned, the rate is almost $96.47 \%$. Among the returned ones, 75 copies are effect, the efficiency of it are $91.46 \%$, showing in the form 2.

Form 2 The statistic in issue and return of questionnaire

\begin{tabular}{|l|l|l|l|lr|}
\hline $\begin{array}{l}\text { Granted } \\
\text { questionnaire }\end{array}$ & $\begin{array}{l}\text { Returned } \\
\text { questionnaire }\end{array}$ & $\begin{array}{l}\text { Effect } \\
\text { questionnaire }\end{array}$ & $\begin{array}{l}\text { Return rate } \\
(\%)\end{array}$ & $\begin{array}{l}\text { Effect rate } \\
(\%)\end{array}$ & \\
\hline 85 & 82 & 75 & 96.47 & 91.46 & \\
\hline
\end{tabular}

comprehensive analysis methods. To make a comprehensive analysis of the efficiency operation system situation of school gyms in our city, and thus improve the system more sound that between school opening practice and theory. 


\section{The result and analysis of research}

To make a survey and analysis the opening situation of school gyms in our city. To analyze the opening extent of school gyms.

According to the Form 3, we find that among the questioned schools, none of them opened every gym to the whole society; there small portion of gyms to open of these school are 7 with $63.64 \%$, and half gyms opens in a school are 3 with $27.27 \%$, only one school opens its most gyms to society with 9.09\%. From this, we know that plenty of schools have disadvantages in opening their whole gyms, and it needs to be improved. With the increasing in fitness command among our citizens, our social sports equipment are very insufficiency.[5] In the such background, it is need more that gyms in every school should be opened to society, and by this to relate the society which improve school images. Offering its sports resource to serve society will meet the fitness commands of people.

Form 3 The survey of school gyms' opening extent at present $(\mathrm{N}=11)$

\begin{tabular}{|l|l|l|l|l|l|}
\hline $\begin{array}{l}\text { Opening extent } \\
\text { of school gyms }\end{array}$ & No opening & Small portion & Nearly half & Most & All \\
\hline $\begin{array}{l}\text { Selection } \\
\text { frequency }\end{array}$ & 0 & 7 & 3 & 1 & 0 \\
\hline$(\%)$ & 0 & 63.64 & 27.27 & 9.09 & 0 \\
\hline
\end{tabular}

To analyze the opening time of school gyms. Among 11 questioned schools, the timing of opening gyms are focus on winter and summer holidays (90.91\%), other holidays (100\%), evenings from Mon. to Fri. (100\%), weekends (90.91\%), showing in the form 4. According to the interview we could know: most schools choose the winter and summer holidays, other holidays and weekend as gym opening timing in order not to affect teaching. [6] Apart from this, it also considers the condition those who take part in, because most of them could dominate their time freely with high rate to join the sports exercise. Thus, schools will choose these timing to open gyms to meet the commands of fitness-wanted people.

Form 4 The survey of opening time of school gyms to society ( $\mathrm{N}=11$ )

(2) To make a survey and analyze the factors that affect the opening condition of school gyms

\begin{tabular}{|l|l|l|l|l|l|l|l|l|}
\hline $\begin{array}{l}\text { opening } \\
\text { time }\end{array}$ & $\begin{array}{l}\text { winter } \\
\text { and } \\
\text { summer } \\
\text { holiday }\end{array}$ & holidays & weekends & $\begin{array}{l}\text { from } \\
\text { Mon.to } \\
\text { Fri. }\end{array}$ & $\begin{array}{l}\text { afternoon } \\
\text { from Mon. } \\
\text { to Fri. }\end{array}$ & $\begin{array}{l}\text { noon } \\
\text { from } \\
\text { Mon. to } \\
\text { Fri. }\end{array}$ & $\begin{array}{l}\text { morning } \\
\text { from } \\
\text { Fon. to }\end{array}$ \\
\hline $\begin{array}{l}\text { selection } \\
\text { frequency }\end{array}$ & 10 & 11 & 10 & 11 & 0 & 0 & 3 \\
\hline$\%$ & 90.91 & 100 & 90.91 & 100 & 0 & 0 & 27.27 \\
\hline
\end{tabular}

The implementation strength and emphasis degree of superiors. After the survey we find that 90.54\% respondents think that the implementation strength and emphasis degree will influent the opening of school gyms largely. [7] The policy government made has leading function, thus every degree government should pay highly attention to the issue of school gyms opening to the society, it should enforce the policy system and organization, investing vast outlay and complete the security system to develop the opening work of gyms with efficiency. It also needs to supervise responsibility of every apartment, emphasizing opening work and do a serious research to make the opening better. [8].

The security problem of school gyms. Security problem is a main factor to hinder school gyms opening to society. After survey we find that $87.84 \%$ respondents think that it is hard to solve the 
security problem if schools open their gyms to the society. [9] The security problems are two kinds: first one is the security problem with those who enter in school to exercise; second one is the security problem of school itself. And the security of school could divide into personal security of students that school valued most and school property security. To ensure students study in a peaceful and well circumstance is what school concerns most. However there are several school injured events happens in recent years that safety of students and school security became the hit to society, it is also a social security problem. There will be many outside school people enter it which possesses largely security danger while most school not check and verify their identity, if school opens its gyms to society. [10] At the same time, sports activity also has great dangers such as football and basketball which against the body severely, and many schools didn't offer professional person to conduct and supervise these people who take part in from outside in order not let them get injury. If there are events occurred with these people, the school will take the responsibility or not? While dealing with such events, the common situation is we can't assure the responsible party and thus, the security problem is a main factor that affect school gym to open or not.

The money school puts are more and more. Through the survey, we find that since school puts more and more money into opening gyms, they are not willing to open it. After survey, it is clear that the fund school grant from educational apartment is going to be organized and planned. As the education investment being strengthened, the quality and number of school gyms are improved. Most schools quip with outdoor playground, rubber and track filed and football field. It is a large outlay to sustain, offer salary to managers and rebuild the gyms, and the opening of school gyms is free for society as national fitness service. As the gyms open to society, the efficiency becomes lager and lager, the payments for gym manage and sustain increased, thus the prime cost increased as well. [11] When the payments that country and local government haven't give enough, it is impossible for school to shoulder most of it, thus the money is another emergency issue for school to solve if while it opens gym to society.

To build operation mechanism of opening school gyms to society. To build policy orientation mechanism. After survey we find that nearly $90 \%$ respondents think that school must build the policy orientation mechanism once it opens gyms to society. Policy orientation mechanism means the government according to the reality and demand to exert its leading function and meanwhile through the deep plan and research, making related policy, enforcing career transportation and service consciousness to push the development of opening gyms to society deeply. It is needs to build policy orientation mechanism if government will make some supporting policy for opening school gyms. Therefore, the government should draft some document to improve the opening of school gyms, and give related benefits to management, investment and tax for school gyms building. At the same time, it also needs to encourage every school to open positively and serve national fitness. Besides that, the government should corporate with related department to communicate well which ensure opening gym project works well.

To build safety precautions mechanism. First of all, people who enter school to exercise should conduct the fitness certificate and swipe the card when in and out. After survey result that among these questioned schools, only one school will check and verify the identity. Therefore, school must be asked to check and verify the certification work when open its gyms to outside, and if the condition allows, it should set a special entrance to make sure a harmony between outside members and school security.

Secondly, school should build security emergency mechanism according to the various security problems. Although our nation has already built the related security measurement for schools opening gyms to society, school still needs to pay attention to the security work and make scientific and efficiency security plan such as assign people to be responsible to security work and these people could pick volunteers from society to help the pubic's security.

To build the fund supporting mechanism. First of all, after survey result, we find that most questioned schools arise money by themselves or rely on outlay from educational department for maintain the gyms. Since schools open their gyms to society, the usage of the gyms increased and the 
fate rate increased as well which leads to a large school invest put into it. Basing on that, government should offer subsidy and build government subsidy mechanism gradually.

Second is to strive for social funds. School leaders should pay highly attention to the opening work of school gyms and invest it as an extent sports items every year. Basing on it, school also need to put related fund into sustaining and adding sports equipments, thus the opening work could be made sure.

\section{Summary}

In a word, the opening of school gyms to society could meet the increased fitness command among the public. At present, in order to assure school gyms opening with order and under leading, it is important to build a sound opening system. Thus we should work hard in this field and let the school could open its gyms in a well condition.

\section{References}

[1]Gao Yuanhua. Study on Present Opening Situation of Secondary Schools in An Qing[D]. Anhui Normal University;,2013.

[2] Fang Dongsheng, Lu Hengbo, Zhang Lihan. Study on Cixi mode of opening sports venues in schools [J]. Sports Culture Guide;,2014(7):114-117.

[3] Jia Hongzhou. Study on the dilemma and Countermeasures of sustainable opening of school stadiums and gymnasiums [J]. Sports Culture Guide,2014(5):141-144.

[4] Yin Xiaomin. How to open and security together -- on the school's safety and security obligations after the opening of school sports venues[J]. Modern Education Science (Higher Education Research),2015(3):14-16.

[5] Wang Zhao, Wang Ming. Research on the problems and Countermeasures of Guangzhou school sports hall opening to the society [J].Sports Teachers,2015(4):76-77,78.

[6] Yang Jian. Analysis of the current situation and influencing factors of school sports venues opening under the background of national fitness [J]. :Contemporary Sports Technology,2016,6(30):149-151.

[7] Qi Xuefeng. Research on the opening of school sports venues in China [J]. Contemporary Sports Technology,2015(35):73-73,75.

[8] Yin Hui. The safety problems of school stadiums and Stadiums Opening to the public [J].Sports,2014,(22):8-9.

[9] Yan Caihong, Lu Hengbo, Xu Yi. Government, community and school cooperation: open model of school sports venues [J]. Zhejiang Sports Science,2016,38(5):77-80.

[10]Cai Yahong,Mu Daoxin. On the reorientation of school sports stadiums to the public -- Also discussing the opening of schools to the society [J].Liao Education,2014(2):40-42.

[11]LI Chunlan. Rational thinking on opening of school sports venues [J]. Journal of Shaanxi Institute of Socialism,2014(2):58-60. 